\title{
О ЕДИНСТВЕ И ДИФФЕРЕНЦИАЦИИ В ПРАВОВОМ РЕГУЛИРОВАНИИ ТРУДА ЖЕНЩИН
}

\author{
А.В. Дзюбак, \\ младший научный сотрудник сектора трудового права и права социального обеспечения \\ Института государства и права Российской академии наук (ИГП РАН)
}

В статье показано, что основу единства правового регулирования труда в РФ составляет конституционное равенство возможностей всех граждан без какой-либо дискриминации вступить в трудовые отношения, реализуя принцип свободы труда. Целью же дифференциации правового регулирования труда женщин является создание им более благоприятных условий для реализации функции материнства, охрана в дальнейшем интересов матери и ребенка.

Ключевые слова: принцип свободы труда, гендерное равенство, труд женщин, единство и дифференциация.

\section{ON UNITY AND DIFFERENTIATION IN THE LEGAL REGULATION OF WOMEN'S WORK}

\section{A.V. Dzyubak}

The article shows that the basis of the unity of legal regulation of labor in the Russian Federation is the constitutional equality of opportunities for all citizens, without any discrimination, to enter into labor relations, implementing the principle of freedom of labor. The purpose of differentiation of legal regulation of women's work is to create more favorable conditions for the implementation of the function of motherhood, protection of the interests of mother and child in the future. Keywords: the principle of freedom of work, gender equality, women's work, unity and differentiation.

Для того чтобы обеспечить единство в регулировании труда женщин, необходимо использовать не только общие нормы трудового законодательства, применяемые ко всем гражданам, но и специальные нормы, распространяющиеся только на лиц женского пола. Взаимозависимость общих и специальных норм в науке трудового права рассматривается в свете такого явления, как единство и дифференциация. Нельзя не отметить, что всякое единство (равенство) должно быть установлено на уровне Основного закона страны в целях недопущения какой-либо дискриминации.

Для трудового права, как и для любой другой отрасли российского права, характерным является его единство, свидетельствующее о внутренней, неразрывной связи всей совокупности норм, регулирующих общественные отношения в сфере наемного труда.

Трудовое право как самостоятельная отрасль права обладает рядом характеризующих его специфических особенностей, к числу которых можно отнести дифференциацию трудового законодательства.

Как справедливо отмечается в литературе, дифференциацию правового регулирования трудовых отношений нельзя правильно понять, не выяснив вначале основные факторы, определяющие единство трудового права [1].

Что касается единства, то оно составляет характерную черту трудового пра- 
ва на всех этапах его развития. Значение слова «единство» в Большом толковом словаре русского языка раскрывается как «общность, цельность, отсутствие дробления, неделимость» [2].

Если дифференциация способствует единству трудового права, то единство создает условия для дифференциации правового регулирования труда [3].

По мнению Р.3. Лившица, «единство только тогда оказывается подлинным, когда оно дифференцировано, а дифференциация достигает цели только тогда, когда она едина... Иными словами, нет единства без дифференциации и нет дифференциации без единства» [4].

Единство трудового права обеспечивается также принципом равенства, который пронизывает правовые положения, определяющие предпосылки возникновения трудовых правоотношений и их содержание. Этот принцип лежит в основе трудовой правосубъектности, которая одинакова для всех граждан независимо от возраста, пола, национальности и расы, физиологических и иных признаков [5].

Именно поэтому вопросам гендерного равенства уделяется большое внимание как в национальном законодательстве, так и в международном.

Положением ч. 3 ст. 19 Конституции РФ установлено гендерное равенство, то

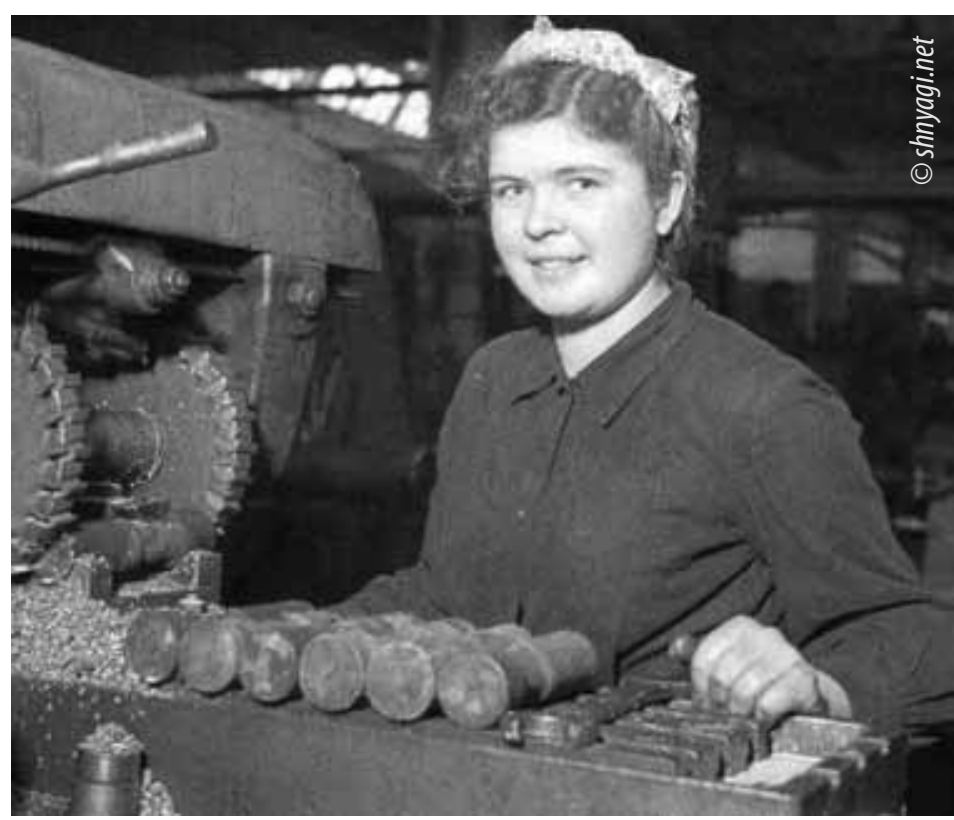

есть закреплено, что мужчина и женщина имеют равные права и свободы и равные возможности для их реализации.

Во Всеобщей декларации прав человека (1948) указано, что все люди рождаются свободными и равными в своем достоинстве и правах (ст. 1), права и свободы устанавливаются без какого бы то ни было различия, включая и по половому признаку (ст. 2).

Так, с момента основания МОТ вопросам гендерного равенства и правам женщин уделялось достаточно много внимания, еще в преамбуле Устава МОТ 1919 года было сказано, что всеобщий и прочный мир может быть установлен только на основе социальной справедливости. Что неизбежно предполагает наличие равного подхода к регулированию труда мужчин и женщин, обеспечение равенства в сфере труда.

Показателем единства трудового права является прежде всего наличие самого ТК РФ - единого кодифицированного акта, закрепляющего в ст. 1 единые цели и задачи трудового законодательства, распространяющегося на всю территорию России и на всех работников независимо от того, где бы они ни работали [6].

Правовые основы категории «единство» установлены ст. 37 Конституции РФ. Устанавливая свободу труда, запрет принудительного труда, вознаграждение за труд без какой-либо дискриминации, труд в условиях безопасности и гигиены, а также право на отдых, законодатель указал на реализацию социально-трудовых прав трудящихся независимо от субъективных и объективных факторов.

Так, правовое регулирование трудовых отношений основывается на принципе единства основных условий труда и равенства трудовых прав и обязанностей всех работников, работающих по трудовому договору. В основе такого единства - конституционное равенство возможностей всех граждан без какой-либо дискриминации вступить в трудовые отноше- 
ния, реализуя принцип свободы труда (ст. 37 Конституции РФ).

Данное конституционное направление отражено и в нормах ТК РФ, с первых статей которого можно выявить общность правовых норм, выраженных прежде всего в принципах трудового законодательства (ст. 2), а именно - установление принципа равенства, запрета дискриминации, которые относятся ко всем категориям работников и работодателей, а ст. 3 предусматривает дифференциацию в трудовых отношениях. Напрямую законодатель не применяет термин «дифференциация», поясняя лишь, что именно не является дискриминацией.

Речь идет об установлении различий, исключений, предпочтений, а также ограничений прав работников, которые определяются свойственными данному виду труда требованиями либо обусловлены особой заботой государства о лицах, нуждающихся в повышенной социальной и правовой защите (подробнее см. ст. 3 ТК РФ).

Однако единство в целом основных принципов правового регулирования отношений сферы трудового права и общих норм трудового права не исключает дифференциации, то есть различий или разнообразия в средствах правового регулирования трудовых отношений некоторых категорий работников [6].

Единство и дифференциация, находясь в неразрывной связи, типичны для трудового права: для обеспечения единства в регулировании трудовых отношений используется учет различных факторов. В свою очередь, дифференциация может быть обеспечена только на основе единых норм трудового права. Таким образом, дифференциация индивидуализирует общую правовую норму в отношении отдельных категорий работников.

Дифференциация, по мнению А.Ф. Нуртдиновой и Л.А. Чикановой, «представляет правовой инструмент, позволяющий в рамках одной отрасли права, на основе отраслевых принци-

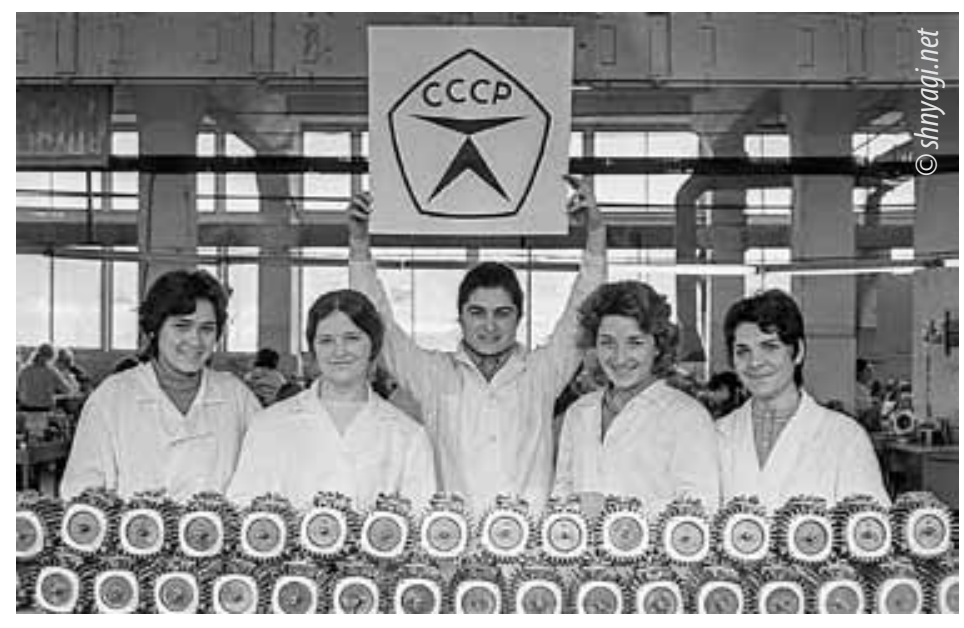

пов правового регулирования учесть специфику общественных отношений, складывающихся в условиях или между субъектами, обладающими определенной спецификой» [7].

Слово «дифференциация» имеет иностранное происхождение (лат. differentie - «различие») и представляет собой разделение, расчленение, расслоение целого на различные части, формы и ступени [8]. Дифференциация норм трудового права представляет собой «разграничение правовых норм на основе юридически значимых факторов в целях конкретизации общих положений трудового законодательства к отдельным категориям работников» [6].

Все основания, которые определяют дифференциацию трудового права, можно разделить на две большие группы: первая группа включает объективные факторы, то есть факторы не связанные с личными особенностями граждан как субъектов трудового права; вторая учитывает факторы личного порядка, характеризующие граждан, которые вступают в трудовые отношения (такую дифференциацию принято называть субъектной) [6].

Конституция РФ в ст. 55 установила, что права и свободы человека и гражданина могут быть ограничены федеральным законом только в той мере, в какой это необходимо в целях защиты основ конституционного строя, здоровья, прав и законных интересов других лиц, обеспечения обороны страны 

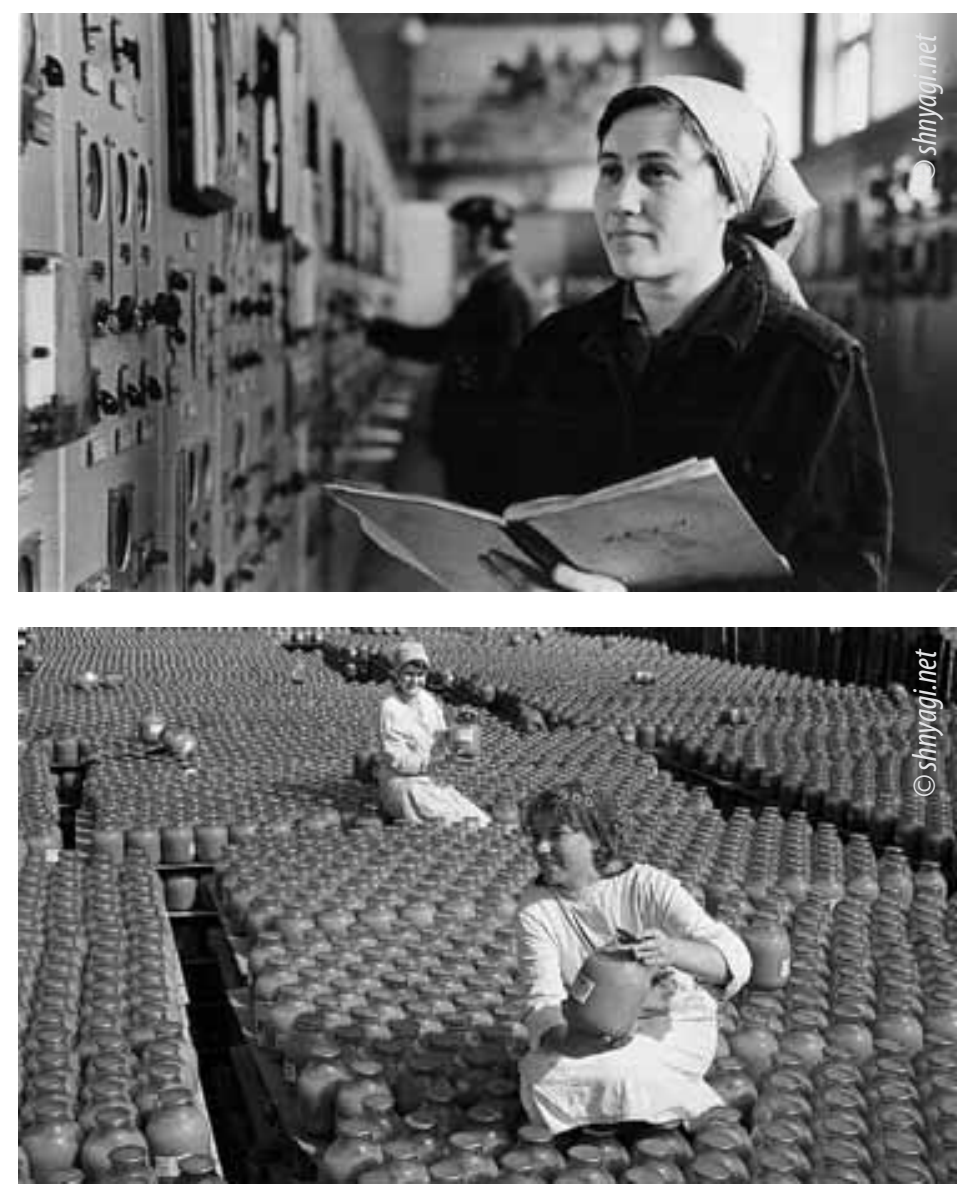

и безопасности государства. Из данного положения Конституции РФ для нас представляет интерес фраза «ограничение в целях защиты здоровья». Представляется, что ограничение прав граждан в связи с состоянием здоровья напрямую связано с реализацией трудовых функций практически любого работника на рынке труда.

Исходя из положений Конституции РФ и ТК РФ можно выяснить общие нормы, распространяющиеся на всех субъектов трудового права независимо в том числе и от гендерной принадлежности. Но ТК РФ предусмотрел и дифференцированный подход к регулированию труда женщин: глава 41 ТК РФ посвящена особенностям регулирования труда женщин и лиц с семейными обязанностями.

Следует отметить, что положения главы 41 ТК РФ напрямую отражают и расширяют положения Конституции РФ в части норм, определяющих Российскую Федерацию в качестве социального государства. Что предусматривает охрану труда и здоровья людей, обеспечение государственной поддержки семьи, материнства, отцовства и детства, установление пособий и иных гарантий. ТК РФ устанавливает определенные рамки действия норм о равенстве, а значит, и о единстве, запрещая какую-либо дискриминацию.

Но в то же время предусмотрены и нормы дифференциации, которые впоследствии более детально раскрыты в разделе XII «Особенности регулирования труда отдельных категорий работников» части четвертой ТК РФ.

Как известно, наиболее общими факторами дифференциации, которые учитывались и всегда учитываются в правовом регулировании трудовых отношений, являются половозрастные особенности граждан и состояние их здоровья. Выделение в законодательстве РФ особых субъектных групп (женщин и несовершеннолетних) свидетельствует о социальной их защите с учетом половозрастных особенностей.

В трудовом законодательстве как советского периода, так и в настоящее время правовое регулирование труда женщин включает две группы норм: одна группа норм распространяется на всех женщин без исключения, другая - лишь на определенную их категорию, поскольку действует только в отношении женщин, выполняющих функцию материнства.

Нормы-дифференциации, регламентирующие труд женщин, установлены главным образом в институтах трудового договора (при приеме на работу, переводах и увольнении), в области рабочего времени и времени отдыха, охраны труда.

Так, специальные нормы предусматривают дополнительные гарантии для женщин при приеме на работу (ст. 64 ТК РФ), особый порядок их перевода на другую работу, исключающий воздействие неблагоприятных производственных факторов, с сохранением среднего заработка по прежней рабо- 
те (ст. 254 ТК РФ), запрещение увольнения по инициативе работодателя в связи с исполнением ими функции материнства, кроме случаев ликвидации организации либо прекращения деятельности индивидуальным предпринимателем (ст. 261 ТК РФ).

К дифференцированному правовому регулированию рабочего времени относятся также правила о запрете для беременных женщин при направлении в служебные командировки, о привлечении к сверхурочной работе, работе в ночное время, выходные и нерабочие праздничные дни. Дополнительные гарантии предусмотрены и для женщин, имеющих детей в возрасте до трех лет, относительно которых действует правило о получении их письменного согласия при направлении в служебные командировки, о привлечении к сверхурочной работе, работе в ночное время, выходные и нерабочие праздничные дни. Должно быть соблюдено условие, что это им не запрещено в соответствии с медицинским заключением (ст. 259 ТК РФ).

Целью дифференциации правового регулирования труда женщин являются создание им более благоприятных условий для реализации функции материнства, охрана в дальнейшем интересов матери и ребенка. Этому, в частности, способствуют и нормы о предоставлении работающим женщинам-матерям дополнительных оплачиваемых перерывов для кормления ребенка (ст. 258 ТК РФ).

Специальные нормы, относящиеся к охране труда, касаются сферы применения труда женщин. Так, согласно ст. 253 ТК РФ, В интересах сохранения здоровья женщины и ее трудоспособности, а также в интересах здоровья будущего поколения государство в законодательном порядке ограничивает применение труда женщин на работах с вредными и (или) опасными условиями труда, а также на подземных работах, за исключением некоторых нефизических работ или работ по санитарному и бытовому обслуживанию (Перечень тяжелых работ и работ с вредными и опасными условиями труда, при выполнении которых запрещается применение труда женщин, утвержден постановлением Правительства РФ от 25.02.2000 № 162). Запрещается применение труда женщин на работах, связанных с подъемом и перемещением тяжестей, превышающих предельно допустимые для них нормы (постановлением Совета Министров - Правительства РФ от 06.02.1993 № 106 (САПП, 1993, № 7, ст. 566) установлены и предельно допустимые нормы нагрузок для женщин при подъеме и перемещении тяжести вручную).

Таким образом, группы норм о дифференциации труда женщин имеют единую направленность, преследуя двуединую цель: а) установление дополнительных гарантий охраны труда женщин; б) создание благоприятных условий для вовлечения женщин в сферу труда.

\section{Библиографический список}

1. Иванов С.А., Лившиц Р.З., Орловский Ю.П. Советское трудовое право: вопросы теории. - М., 1978. - С. 324.

2. Большой толковый словарь русского языка / Под ред. Д.Н. Ушакова. - М., 2008. - C. 229.

3. Советское трудовое право: вопросы теории. - С. 317.

4. Лившиц Р.3. Заработная плата в СССР: Правовое исследование. - М., 1972.-С. 39.

5. Советское трудовое право: вопросы теории. - С. 326.

6. Скачкова Г.С. Расширение сферы действия трудового права и дифференциации его норм: Монография. - М., 2003. - С. 204.

7. Нуртдинова А.Ф., Чиканова Л.А. Дифференциация регулирования трудовых отношений как закономерность развития трудового права // Журнал российского права. - 2015. — № 6. - С. 70.

8. Чудинов А.Н. Словарь иностранных слов, вошедших в состав русского языка. - СПб., 1910. - С. 171. 